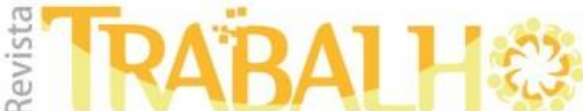 \\ (En)Cena
}

\section{"A GRANDE QUESTÃO PARA SER PROFESSOR É SABER CRIAR MECANISMOS PARA NÃO ADOECER": PRAZER E SOFRIMENTO NO TRABALHO E AS ESTRATÉGIAS ELABORADAS POR DOCENTES DE ESCOLAS ESTADUAIS}

"The big issue to be a teacher is to know how to create mechanisms to prevent illness": pleasure and suffering at work and the strategies developed by state schools teachers

"La grande question d'être un enseignant est de savoir créer des mécanismes pour ne pas tomber malade": le plaisir et la souffrance au travail et les stratégies développées par les enseignants des écoles d'état

"La gran cuestión para ser profesor es saber crear mecanismos para no enfermarse": placer y sufrimiento en el trabajo y las estrategias elaboradas por docentes de escuelas estaduales

Yohanna Breunig 1 Psicóloga, Mestranda em Educação pela Universidade de Santa Cruz do Sul - UNISC (Bolsista PROSUC/Capes). Psicóloga, graduada em Psicologia pela Universidade de Santa Cruz do Sul - UNISC. Integrante do Grupo de Pesquisa Educação, Trabalho e Emancipação - PPGEdu/UNISC

Karine Vanessa Perez ${ }^{2}$

Psicóloga, Doutora e Mestre em Psicologia Social e Institucional pela Universidade Federal do Rio Grande do Sul - UFRGS . Docente da Universidade de Santa Cruz do Sul - UNISC. Psicóloga, graduada em Psicologia pela Universidade do Oeste de Santa Catarina - Campus de São Miguel do Oeste (2007). Integrante do Laboratório de

Psicodinâmica do Trabalho - PPGPSI/UFRGS.

\begin{abstract}
Resumo
O presente artigo é resultado de uma pesquisa qualitativa, que contou com a participação de oito professores do município de Santa Cruz do Sul/RS. Tem como objetivo investigar como a organização de trabalho atua na produção de prazer e sofrimento de professores de escolas públicas, considerando as estratégias (defensivas, de permanência do sujeito no trabalho e de mobilização subjetiva e coletiva) elaboradas para evitar o adoecimento. Para tanto, utilizou-se uma adaptação da metodologia strictu sensu da Psicodinâmica do Trabalho. A partir da análise e interpretação dos dados, constatou-se que o reconhecimento dos alunos é a maior fonte de prazer dos professores, motivando-os a continuar investindo em seu trabalho. Contudo, os docentes revelam haver pouco reconhecimento de sua categoria pela sociedade, além de sentirem-se desestimulados pelos gestores públicos. Destarte, foi evidenciada a necessidade de maiores investimentos na educação e reconhecimento dos professores, para que eles transformem seu sofrimento em prazer, na medida em que compreenderem que seu esforço possui significado.
\end{abstract}

Palavras-chave: Psicodinâmica do Trabalho; Saúde do Trabalhador; Trabalho Docente; Prazer e Sofrimento; Estratégias Defensivas

\footnotetext{
1 yohanna_breunig@hotmail.com

2 karinevanessaperez@gmail.com
} 


\begin{abstract}
The present article is the result of a qualitative field research, which was attended by eight teachers from the municipality of Santa Cruz do SulRS. It aims to investigate how the work organization operates in the production of pleasure and suffering of public school teachers, considering the strategies (defensive strategies, work permanence strategies and subjective and collective mobilization strategies) designed to prevent illness. Therefore, is was used an adaptation of the strictu sensu methodology of Work Psychodynamics. From the analysis and interpretation of the data, it was found that the greatest source of pleasure, which reflects on their investment in work, comes from the students' recognition. However, teachers reveal that there is little recognition of their category by society, besides they feel discouraged by public managers. Thus, it was evidenced the need to invest more in education as well as granting the teachers greater recognition, so they can turn their suffering into pleasure by realizing that their dedication has a meaning.
\end{abstract}

Keywords: Work Psychodynamics; Worker`s Health; Teaching Work; Pleasure and Suffering; Defensive Strategies.

\title{
Résumé
}

Cet article est le résultat d'une recherche qualitative, avec la participation de huit enseignants de la municipalité de Santa Cruz do Sul/RS. Il vise à étudier comment l'organisation du travail fonctionne dans la production de plaisir et de souffrance des enseignants des écoles publiques, en tenant compte des stratégies (défensive, de permanence du sujet au travail et stratégies de mobilisation subjective et collective) conçues pour prévenir la maladie. Pour ce faire, on a été utilisé une adaptation de la méthodologie strictu sensu de la Psychodynamique du Travail. À partir de l'analyse et de l'interprétation des données, il a été trouvé que la reconnaissance des étudiants est la plus grande source de plaisir pour les enseignants, ce qui les motive à continuer d'investir dans leur travail. Cependant, les enseignants révèlent que leur catégorie est peu reconnue par la société, en plus d'être découragés par les gestionnaires publics. Ainsi, a été prouvé la nécessité d'investir davantage dans l'éducation et la reconnaissance des enseignants afin qu'ils transforment leurs souffrances en plaisir en réalisant que leurs efforts ont un sens.

Mots clés: Psychodynamique du Travail; Santé des Travailleurs; Travail d'enseignement; Plaisir et Souffrance; Stratégies Défensives.

\section{Resumen}

El presente artículo es el resultado de una investigación cualitativa, que contó con la participación de ocho profesores del municipio de Santa Cruz do Sul/RS. Se pretende investigar cómo la organización de trabajo actúa en la producción de placer y sufrimiento de profesores de escuelas públicas, considerando las estrategias (defensivas, de permanencia del sujeto en el trabajo y estrategias de movilización subjetiva y colectiva) elaboradas para evitar la enfermedad. Para ello, se utilizó una adaptación de la metodología strictu sensu de la Psicodinámica del Trabajo. A partir del análisis e interpretación de los datos, se ha constatado que el reconocimiento de los alumnos es la mayor fuente de placer de los profesores, motivándolos a continuar invirtiendo en su trabajo. Sin embargo, los docentes revelan poco reconocimiento de su categoría por la sociedad, además de sentirse desestimulados por los gestores públicos. De ahí, se ha evidenciado la necesidad de mayores inversiones en la educación y el reconocimiento de los profesores, para que ellos transformen su sufrimiento en placer, en la medida en que entiendan que su esfuerzo tiene significado.

Palabras clave: Psicodinámica del Trabajo; Salud del Trabajador; Trabajo Docente; Placer y Sufrimiento; Estrategias Defensivas.

\section{Introdução}


Este artigo propõe a reflexão sobre o trabalho docente e os impactos da organização do trabalho na saúde dos professores, visto que esta atividade exige grande dedicação e resiliência, já que esses trabalhadores lidam com constantes adversidades no ambiente escolar. Eles são essenciais para a formação de novos cidadãos, além de abrirem possibilidades para que seus alunos possam escolher um caminho a trilhar no futuro (Santini, \& Molina Neto, 2005).

Contudo, estes profissionais são atravessados por imprevistos e dificuld ades que permeiam o cotidiano escolar, especialmente quando nos remetemos a escolas da rede pública. Precisam lidar com a sobrecarga de trabalho, com a multiplicidade de papéis que acabam por assumir e com a falta de recursos no local de trabalho. Ademais, deparam-se com a falta de reconhecimento de sua profissão, a baixa remuneração e a pouca autonomia que lhes é dada (Neves \& Seligmann-Silva, 2006 \& Santini, \& Molina Neto, 2005).

Tais elementos encontram-se relacionados entre si e intervêm no modo como os docentes desempenham o seu trabalho, assim como interferem na realização profissional, podendo produzir sofrimento e até mesmo prejuízos físicos e psicológicos graves. $\mathrm{O}$ sofrimento dos professores e consequente adoecimento no trabalho são fatores que têm sido visíveis não apenas no âmbito escolar, mas na sociedade em geral, seja pelo contato que as pessoas possuem com esses profissionais, bem como pelas informações que a mídia transmite. (Neves \& Seligmann-Silva, 2006)

Nesse sentido, na tentativa de compreender como os professores lidam com as adversidades e o sofrimento no trabalho, objetivou-se analisar a influência da organização do trabalho na produção de prazer e sofrimento de professores de escolas públicas estaduais, enfocando o uso de estratégias elaboradas neste contexto. Inicialmente, pretendeu-se averiguar estratégias defensivas, mas no decorrer da pesquisa foram encontradas também as estratégias de permanência do sujeito no trabalho e estratégias de mobilização subjetiva e coletiva.

\section{Transformações no mundo do trabalho e saúde docente}

O mundo do trabalho tem passado por inúmeras transformações, tendo em vista o desenvolvimento $\mathrm{e}$ as novas demandas da sociedade. Como parte da população trabalhadora, os docentes também sentiram o impacto de diversas mudanças que ocorreram ao longo dos anos, especialmente a partir da década de 1980, visto que deles se exigia muito sem que houvesse leis que os amparassem. Dentre as modificações impulsionadas pelo 
neoliberalismo, Oliveira e Pires (2014, p. 75) apontam que esse "[...] representou o estabelecimento de reordenações nos sistemas educacionais, momento em que houve uma redefinição do papel do Estado na sua relação com a educação", estabelecendo uma relação mais empresarial, em que se visava à eficiência e eficácia da escola.

Contudo, no que tange à questão salarial, nota-se que não há uma remuneração exatamente proporcional à importância da profissão. Nesse sentido, Tumolo e Fontana (2008) analisam o passado da carreira de docentes e concluem que uma das possíveis causas para a desvalorização salarial, e também social, advém da época em que as mulheres entraram para o magistério em grande quantidade, provocando tal desvalorização devido a uma questão de gênero.

Frente a tantas dificuldades diariamente enfrentadas pelos docentes, faz-se o questionamento sobre o que os mantêm no exercício de sua profissão, o que leva à reflexão sobre o prazer que o sujeito sente em relação ao seu trabalho. Esse condiz com a sua satisfação e engajamento para realizar as tarefas propostas por sua instituição. Tal sentimento está diretamente ligado à sensação de ser útil àquele lugar, advinda do reconhecimento que seus chefes, colegas ou alunos/familiares manifestam sobre si, ou seja, se dá por meio do olhar do outro. Entretanto, quando isso não ocorre, o sujeito é levado a pensar que todo o seu esforço não valeu a pena, sendo conduzido a um processo de sofrimento (Dejours, Abdoucheli \& Jayet, 1994).

Qualquer profissão produz prazer e sofrimento, mas o sujeito começa a adoecer no momento em que o sofrer no trabalho se torna maior que o prazer. O sofrimento é um sentimento muito presente nas organizações de trabalho e pode ocorrer quando o profissional teme não atingir seus objetivos pode advir da pressão externa e pela desesperança em ser reconhecido pelo seu trabalho (Dejours, 1999). O medo da incompetência pode ocorrer tanto pela falta de reconhecimento, quanto pela diferença entre a organização prescrita e real do trabalho, ocasionando na frustração dos sujeitos.

Nesse sentido, a questão do reconhecimento é percebida como um componente essencial para que os trabalhadores deem um sentido àquilo que realizam, servindo de impulso para darem continuidade às tarefas, com dedicação e empenho, além de reafirmar que seu trabalho está sendo efetivo e que é necessário ao meio social (Dejours, 1999). É, portanto, “[...] decisivo na dinâmica da mobilização subjetiva da inteligência e da personalidade no trabalho" (Dejours, 1999, p. 34). Esse autor refere que, a partir do reconhecimento, todas as angústias, 
dúvidas, investimento e decepções referentes ao trabalho passam a ter um sentido, compensando a parcela de sofrimento, já que sua dedicação foi benéfica à organização do trabalho.

Desse modo, é possível pensar que o sujeito transforma e constitui a sua subjetividade e identidade por meio do seu trabalho e das relações que lá estabelece, posto que assim como ele influencia, também é influenciado pelo meio no qual está inserido. Portanto, o trabalho é dotado de significado para o sujeito que o realiza, trazendo um sentido para a sua vida. Por conseguinte, a Psicodinâmica do Trabalho (PdT) considera a importância do reconhecimento do sujeito pelo outro como forma de dar sentido à sua atividade e como possibilidade de (re) significar a sua experiência no ofício (Dejours, 1999).

Entretanto, quando

reconhecimento não aparece, abre-se espaço para a emergência do sofrimento, que se manifesta de diferentes formas, de acordo com a vivência do sujeito, permeando todos os âmbitos de sua vida, podendo levar ao adoecimento. Este sofrimento pode ser manifestado a partir da relação com alunos inquietos e que transgridem as regras, frente à falta de recursos nas escolas, à baixa remuneração, à falta de reconhecimento do trabalho docente, ao desânimo em preparar atividades aos alunos e não conseguir realizá-las, dentre tantos outros motivos evidenciados pelos mesmos (Duarte \& Mendes, 2015 \& Neves \& Seligmann-Silva, 2006).

Justamente visando driblar as dificuldades encontradas no cotidiano de trabalho, tentando burlar (ou pelo menos lidar com) o sofrimento a que estão expostos, os profissionais se veem na necessidade de encontrar meios para evitar o adoecimento físico e psíquico. Dessa forma, acabam utilizando estratégias defensivas, as quais podem ocorrer tanto individual, como coletivamente. Igualmente, estas podem ser conscientes ou inconscientes para o sujeito (Dejours, 1999).

Tais estratégias de defesa conseguem fazer com que os docentes se adaptem às pressões do trabalho, alcançando seu objetivo de afastar o sofrimento e, principalmente, o adoecimento (Dejours, 2004b). No entanto, isso não significa que elas sejam totalmente benéficas, pois ao mesmo tempo em que protegem a saúde do trabalhador, evitam que a organização do trabalho seja modificada. Isso porque os profissionais, ao internalizarem essas defesas, passam a não questionar a sua existência, o que gera uma alienação e consequente reprodução das mesmas (Dejours, Abdoucheli \& Jayet, 1994; Bottega, Perez \& Merlo, 2013). 
Santini e Molina Neto (2005) demonstram, em sua pesquisa, que muitos docentes acabam por faltar ao trabalho sem dar justificativa, fazem apenas o mínimo exigido dentro de sala de aula, sem conseguirem estabelecer um bom relacionamento com os seus alunos. Entende-se, assim, que as estratégias defensivas servem como meio de manter o sujeito no exercício da sua profissão, sem que o mesmo adoeça, lidando com o sofrimento e com as dificuldades do cotidiano através de diferentes atitudes.

Por outro lado, os docentes também podem elaborar estratégias de permanência do sujeito no trabalho ${ }^{1}$, em que eles encontram maneiras mais positivas do que as estratégias defensivas para lidar com as situações adversas e evitar o adoecimento. No mesmo sentido que as estratégias de resistência, propostas por Perez (2017, p. 229), é como se as estratégias de permanência do sujeito no trabalho "estivessem um passo a frente das defensivas, sendo menos primitivas e mais conscientes".

Portanto, elas encontram-se "no espaço entre as defesas, que alienam os sujeitos da realidade vivida, e a mobilização coletiva que possibilita a transformação da organização do trabalho" (Perez, 2017, p.
229). Dentre as estratégias possíveis encontram-se o bom relacionamento com os alunos, a conscientização e o estabelecimento de limites. Trata-se de alternativas que trazem benefícios ao contexto escolar e à subjetividade dos docentes, embora isso não signifique que irão alterar a organização do trabalho.

Ainda foi possível perceber estratégias de mobilização subjetiva e coletiva, as quais se referem a ações coletivas dos trabalhadores na tentativa de "eliminar o custo humano negativo do trabalho, ressignificar o sofrimento e transformar em fonte de prazer a organização, as condições e as relações socioprofissionais" (Freitas \& Facas, 2013, p. 11). Tais estratégias se fazem presentes por meio de relacionamentos positivos com os colegas de trabalho, em que ocorre a cooperação, bem como através de espaços públicos de discussão.

\section{A metodologia em psicodinâmica do trabalho}

Para a realização da presente pesquisa foi utilizada a metodologia em Psicodinâmica do Trabalho (PdT), elaborada por Christophe Dejours (2004a). Essa tem o objetivo de compreender como as relações e a organização do trabalho

\footnotetext{
3 Termo des envolvido pelas pesquis adoras, que se as semelha às estratégias de resistência propostas por Perez (2017).
} 
mobilizam os aspectos psíquicos e subjetivos do sujeito (Heloani \& Lancman, 2004), sendo composta pela pré-pesquisa, a pesquisa propriamente dita, a análise $\mathrm{e}$ interpretação dos dados e a validação, que neste caso foi intermediada pela perlaboração.

Ressalta-se aqui que apesar de ser adotada a metodologia da PdT, é necessário levar em conta que nem tudo o que foi pensado pelo autor se adequa à realidade brasileira de pesquisa, já que suas ações foram pensadas no contexto francês e no Brasil são encontrados alguns aspectos diferentes. O que se quer dizer é que na França é muito comum que as próprias instituições procurem profissionais para realizar uma pesquisa-ação, em que a demanda surge dos próprios trabalhadores. Entretanto, no Brasil não é costumeiro presenciar esse tipo de iniciativa, o que acarreta na identificação da demanda por parte dos profissionais/pesquisadores, a partir do que cada um percebe como fator relevante a ser investigado. De mesmo modo, há algumas peculiaridades que podem ser encontradas em cada situação de trabalho, indicando a necessidade de adaptações, sem que haja comprometimento da integridade da metodologia (Heloani \& Lancman, 2004).

Assim sendo, destaca-se que esta pesquisa emergiu a partir de uma demanda previamente estabelecida, em que já se chegou ao campo com a intenção de compreender a dinâmica de prazer e sofrimento dos docentes de escolas estaduais do município de Santa Cruz do Sul/RS, verificando a existência de estratégias elaboradas pelos mesmos. Nesse sentido é referida uma das adaptações à metodologia strictu sensu (Perez, 2012), assim como o fato de não terem sido realizados encontros de grupo (entrevistas coletivas) com o público-alvo, como Dejours enfatiza em seus estudos. Optou-se por utilizar entrevistas individuais para a coleta do material, alternativa que tem sido bastante adotada em pesquisas brasileiras (Perez, 2012, Bottega, 2015 \& Mattos, 2016), em função da dificuldade de reunir docentes em um grupo, devido sua carga horária exaustiva e que se estende para diferentes turnos. Todavia, a análise e discussão dos dados foram feitas com enfoque no coletivo, observando a categoria e não questões individuais.

Após a realização da pré-pesquisa, que consistiu em prévia revisão bibliográfica acerca da temática a ser estudada, bem como busca de informações sobre o campo de pesquisa, partiu-se para a pesquisa propriamente dita. Essa incidiu na realização da investigação de campo, para a qual foi utilizada a metodologia de pesquisa qualitativa (Silveira \& Córdova, 2009), buscando aprofundar o entendimento sobre a categoria profissional docente através da 
realização de entrevistas individuais semiestruturadas com oito professores de diferentes escolas estaduais do município de Santa Cruz do Sul/RS. A escolha do público-alvo ocorreu por meio da metodologia da Bola de Neve (Snowball), em que cada entrevistado indicava o próximo, criando uma espécie de rede (Baldin \& Munhoz, 2011).

A fim de preservar as identidades dos entrevistados foram utilizadas identificações fictícias para se referir a seus comentários verbais, optando por empregar nomes de flores. Assim como uma flor é plantada e deve ser regada com frequência, necessitando de cuidados para florescer, o trabalho do professor tem essa semelha nça. A cada dia o professor vai contribuindo mais para o desenvolvimento do aluno, o que às vezes pode ser um processo lento, mas que contribui para a formação do mesmo, fazendo-o "florescer" e preparando-o para a vida. Sendo assim, cada docente pôde escolher o nome da flor de sua preferência.

Vale ressaltar que a participação dos sujeitos foi de livre vontade, em que foram explicados os objetivos e demais questões concernentes à pesquisa e foi entregue um Termo de Consentimento Livre e Esclarecido (TCLE) para que assinassem, caso estivessem de acordo. Ademais, o projeto desta pesquisa foi previamente encaminhado à Plataforma Brasil e submetido ao Comitê de Ética em Pesquisa envolvendo seres humanos, tendo sido aprovado. Somente após a aprovação é que se pôde dar prosseguimento à pesquisa, iniciando a coleta de dados. Portanto, esta pesquisa recebeu o Certificado de Apresentação e Apreciação Ética (CAAE) sob o número 62725216.2.0000.5343.

À vista disso, dentre os docentes participantes a média de idade foi de 36 anos, em que as idades variaram de 28 a 45 anos. Destes, seis são mulheres e dois, homens, sendo todos estatuários (concursados no Estado). Em relação ao tempo de atuação na escola atual constatouse tanto professores que estão há um ano no mesmo local, quanto outros que já estão há dezessete anos, resultando em uma média de 6,43 anos. Sete docentes possuem ensino superior completo e uma ainda está cursando a faculdade. A formação dos professores é bem variada, apesar de a grande maioria ter cursado pedagogia. Três destes referiram ter pós-graduação e apenas dois fizeram o magistério antes de ingressar na faculdade.

Em relação à carga horária, cinco destes docentes permanecem 40 horas semanais na mesma escola, embora dos demais que referiam trabalhar 20 horas na mesma escola, dois tenham referido trabalhar mais 20 horas semanais em outra escola (totalizando 40 horas semanais). Ademais, foi possível entrevistar sujeitos de 
escolas variadas, o que possibilitou a compreensão de diversas realidades.

No que tange à análise e interpretação dos dados, salienta-se que o espaço da entrevista propiciou não apenas a coleta de informações, mas uma oportunidade de fala e de escuta, propiciando uma autorreflexão por parte dos docentes. A análise teve como foco o coletivo, premissa importante na metodologia da PdT (Dejours, 2004a), não por querer desconsiderar a individualidade de cada um, que é sabido que existe, mas por almejar compreender questões pertinentes e que se apresentam no coletivo (Perez, 2012, \& Mattos, 2016), representando alguns aspectos da categoria docente. Essa foi feita por meio da análise e interpretação dos comentários verbais dos participantes, em que se buscou elementos que fossem comuns à maioria do coletivo.

A última fase da metodologia da PdT remete à validação da pesquisa por parte dos próprios participantes. No caso desta pesquisa, a validação foi intermediada pela elaboração/perlaboração e ambas ocorreram durante $\mathrm{o}$ próprio ato das entrevistas $^{2}$. A perlaboração (Dejours, 2004a) foi evidenciada na medida em que os docentes repensaram o seu trabalho e se

4A validação ocorreu diretamente por meio das entrevistas, devido à adaptação da metodologia strictu sensu da PdT, em que não houve a possibilidade de fazer a posterior discussão coletiva dos resultados (Perez, 2012, \& Mattos, 2016). deram conta de seus afazeres, bem como refletiram sobre si mesmos e sobre a organização de trabalho. Todos evidenciaram a importância das entrevistas e sentiram-se agradecidos por terem esse espaço de fala e escuta, percebendo-se até mesmo valorizados, emocionados e reconhecidos a partir do interesse das pesquisadoras para com o seu fazer, o que favoreceu a elaboração/perlaboração do prazer e sofrimento vivenciados no trabalho e a consequente validação da pesquisa.

Mendes (2007, p. 32) complement a que "[...] a fala permite resgatar a capacidade de pensar sobre o trabalho, é um modo de desalienação, bem como uma possibilidade de apropriação e dominação do trabalho pelos trabalhadores [...]”. Amarilis, uma das participantes, retrata bem esse sentimento evidenciado pelo coletivo ao enunciar que "um professor deveria ter um grupo de apoio pra conversar [...] colocar pra fora essas angústias [...] obrigada por ter me escolhido".

\section{Tecendo discussões a partir dos}

\section{resultados}

A fim de compartilhar alguns dos resultados da pesquisa e tecer discussões acerca das mesmas, pensando no modo com

Contudo, os participantes conseguiram dar um retorno sobre o que a entrevis ta foi capaz de produzir no sentido de fazer pensar sobre o trabalho e seus reflexos na subjetividade dos trabalhadores. 
o trabalho atua sobre os sujeitos e viceversa, foram elencados três eixosnorteadores, sendo eles: organização do trabalho; dinâmica de prazer e sofrimento da categoria docente; e estratégias elaboradas pelos docentes.

\section{Organização do Trabalho}

Entende-se por organização do trabalho "a divisão das tarefas e dos homens no mundo do trabalho", em que são estabelecidas as prescrições do mesmo, com a finalidade de nortear, orientar e fiscalizar o trabalhador para que desempenhe um bom trabalho (Anjos, 2013, p. 272). Contudo, a organização do trabalho não se restringe apenas ao trabalho prescrito, visto que na prática os trabalhadores se deparam com imprevistos que exigem adequações de determinadas tarefas, sendo esse o trabalho real (Anjos, 2013).

Quando remetida aos professores de escolas estaduais, a organização de trabalho também diz respeito tanto à burocracia exigida pelo Estado, à programação das aulas e à rotina do ambiente escolar, quanto às relações estabelecidas entre os colegas de trabalho, o sistema hierárquico, às relações de poder e às estratégias elaboradas pelos docentes para lidarem com as adversidades do cotidiano (Dejours, 1992). Refere-se ainda ao próprio "não-dito" do trabalho, àquilo que está nas entrelinhas e, muitas vezes, também acaba regendo ou pelo menos influenciando o funcionamento do trabalho.

Sendo assim, o modo como a sociedade compreende a escola e sua visão sobre 0 trabalho docente também repercutem na organização de trabalho e afetam os professores (Santini \& Molina Neto, 2005). Nesse sentido, alguns participantes da pesquisa enunciaram o quanto consideram que os professores não são mais respeitados da mesma forma, visto que pensam que antigamente não só os alunos, mas também seus pais e a sociedade em geral os respeitavam muito mais, percebendo-os como uma figura que representava certa autoridade, um ser detentor de um saber e uma referência social.

[...] muito da questão da autoridade e de como era antigamente tá se perdendo e isso tá dificultando bastante o trabalho do professor [...] antigamente o professor era mais valorizado (Amarilis).

A comunidade escolar já não vê mais o professor como aquela figura de autoridade e que merece respeito (Margarida).

Da mesma maneira que os docentes têm percebido essa possível minimização do respeito por sua profissão, há outros atravessamentos que, às vezes, podem 
dificultar o bom rendimento das atividades. Deste modo, emerge a temática das relações de poder que costumam aparecer nos ambientes de trabalho sob forma de relações autoritárias e de controle (Dejours, 1992).

Nesse sentido, pode-se pensar em diferentes relações em que isto ocorre, tanto dentro do próprio estabelecimento escolar entre direção e professores ou entre estes e seus alunos, quanto entre o Estado e a escola, em que aquele tem o poder de decisão sobre muitas normativas de escolas públicas estaduais. Infelizmente, nem sempre as determinações vindas do Estado são tão eficazes quanto deveriam ser, a exemplo de quando esse resolve implantar mudanças sem que haja a participação docente. Conforme Guzzo, Mezzalira e Moreira (2014, p. 222), “a determinação sobre quais políticas devem, ou não, ser implementadas acaba por ser uma decisão de quem está no poder e menos uma construção voltada para o entendimento efetivo das necessidades postas".

\section{[...] agora vem a lei e muda tudo de novo e quem faz a lei não são os professores, não é quem sabe a vivência (Amarilis).}

Percebe-se que os participantes além de compreenderem essa hierarquia vertical que existe entre o Estado e suas escolas (e, consequentemente, o modo como o trabalho deve ser realizado), identificam o olhar que aquele tem sobre as instituições de ensino e seus servidores, como se fossem empresas e empregados. Eé nesse modelo que o Estado tem pensado suas decisões para a educação, mesmo que de forma indireta, onde se prima por produtividade e quantidade (a exemplo de turmas superlotadas), ao invés de qualidade de ensino (Tumolo \& Fontana, 2008).

Entretanto, todas essas ações acabam por prejudicar muitas das práticas que poderiam ser pensadas no ambiente escolar. Isso pode resultar no desinteresse dos docentes em criarem inovações nesse espaço, refletindo no modo como trabalham com os alunos. Essa questão também aparece por meio de outro tipo de relação hierárquica vertical que ocorre na organização de trabalho, em que os docentes demonstram certa insatisfação referente a determinadas atitudes da gestão da escola, como mostram os comentários verbais a seguir.

[...] cada ano que passa a gente vai perdendo a autonomia. Essa questão de gestão democrática muitas vezes não é nada democrática, é assim e deu. Tu não tem opção de mudar, de questionar (Amarilis).

[...] às vezes acho que a direção da escola acaba tolhendo muito, sabe. Tu não poder se expressar (Rosa). 
Destarte, infere-se o quanto essas relações entre Estado-escola e direçãodocentes constituem a organização de trabalho e influenciam na maneira como o trabalho será realizado. Não é possível negar que o trabalho se tornou, há muito tempo, essencial na vida do sujeito, em que este o procura não apenas com a finalidade de obter estabilidade financeira (embora esta seja demasiadamente relevante), mas também com o objetivo de interação social, já que é através do trabalho que moldamos nossa subjetividade (Dejours, 2004b).

[...] isso aqui pra mim é a minha segunda casa, né [...] a gente passa mais tempo aqui do que em casa (Gérbera).

Apesar de o exemplo acima se referir mais especificamente ao local de trabalho, pode-se pensar na importância de uma organização de trabalho bem amparada e que possa favorecer seus trabalhadores. Afirma-se isso dado o valor que eles atribuem ao seu trabalho, bem como o tempo que despendem realizando suas atividades laborais.

Sabe-se que ainda há muito a melhorar, principalmente quando se pensa em nível de educação, como um todo, e categoria docente. Nesse sentido, é relevante considerar de que modo a organização de trabalho tem atuado na dinâmica de prazer e sofrimento dos professores, para compreender o que os mantêm no exercício de seu ofício.

\section{Dinâmica de Prazer e Sofrimento na}

\section{Categoria Docente}

O prazer e sofrimento fazem parte da própria dinâmica do trabalhar, sendo esses elementos centrais para a PdT. O sujeito quando trabalha coloca o seu engajamento e a sua subjetividade no que faz, construindo relações sociais e constituindo aquilo sobre o qual Dejours (2004b) escreveu, a partir de Michel Henry, chamado de corpopropriação do mundo. Este termo se refere ao corpo que o sujeito habita, um corpo afetivo, que se empenha na relação com o outro, não só verbalmente, mas por meio de mímicas, gestos, agressividade e sedução (Dejours, 2004b).

Trata-se de um '[...] corpo subjetivo que se constitui a partir do corpo biológico [...] e é exatamente este corpo resultante da experiência mais íntima de si e da relação com o outro que é convocado no trabalhar" (Dejours, 2004b, p. 29). Contudo, os trabalhadores normalmente se deparam com imprevistos à tarefa prescrita, sendo dominados por certa frustração e sofrimento (mesmo que inconscientemente) por perceberem que não darão conta da atividade tal qual foi exigida. Destarte, eles encontram meios, muitas vezes invisíve is aos olhos das chefias, para desempenharem 
a tarefa, a fim de alcançarem os resultados necessários.

Quando este trabalho é reconhecido pelos outros (colegas, diretores, alunos, pais de alunos, sociedade, governo), o docente percebe a utilidade e o sentido do seu trabalho, compreendendo que mesmo com as adversidades, ele conseguiu cumprir sua atividade. Esse reconhecimento propicia o prazer no trabalho, o que significa que o professor fica grato, feliz e com sensação de dever cumprido. Entretanto, quando o seu esforço e engajamento não são reconhecidos e valorizados por pelo menos um dos grupos acima elencados, o docente sente-se desanimado, sem saber se seu trabalho está sendo realmente efetivo (Dejours, Abdoucheli \& Jayet, 1994).

Não me sinto valorizada como eu gostaria, né, até por ser uma questão de escola pública e a gente sabe que não tem um cuidado mais pessoal, assim, com o trabalho que tu tá fazendo. É o que tu acha que tu faz e deu. Mas sou muito realizada com o trabalho que eu faço (Margarida).

[...] tem anos que tem turmas mais complicadas [...] mas que tu vai trabalhando durante o ano, tu vai conversando com eles. Eu me sinto muito satisfeita com as minhas turminhas, são bem queridos (Rosa).
Percebe-se que ao mesmo tempo em que os professores demonstram cansaço e certa decepção com a atual situação da educação, ainda há muita emoção e carinho ao falar de seu trabalho e de seus alunos, o que ainda os motiva a continuar. Então aparece um misto de sentimentos, em que há prazer e sofrimento associados (Dejours, 1992). Estes docentes conseguem perceber que o sofrimento pode se transformar em prazer e sua maior satisfação vem ao acompanharem o desenvolvimento dos seus alunos e estabelecerem uma relação afetiva positiva com os mesmos.

[...] eu tenho uma relação super boa com meus alunos. [...] eu gosto do ambiente escolar, eu me sinto bem lá (Hibisco).

[...] o que me faz continuar é ver essa evolução deles, ver como eles vão crescendo e o quanto a gente aprende com eles (Lírio).

É notável o carinho que os docentes manifestam por seus alunos, o que também foi possível evidenciar a partir de suas expressões faciais, em que transparecia a felicidade em falar sobre $\mathrm{o}$ afeto $\mathrm{e}$ reconhecimento dos alunos. Todavia, os professores demonstram diferentes fatores que desmotivam o seu trabalho e que podem levar ao sofrimento, como desvalorização social e salarial e sobrecarga de trabalho. Frustração por não conseguirem realizar sua 
atividade do modo como desejavam também é um fator recorrente de angústia, gerando autocobrança e sofrimento.

A gente tem a visão que o professor muda o mundo. Eu ainda acredito nisso, que a educação pode mudar o mundo. Mas infelizmente o dia a dia do professor faz a gente desacreditar. No fundo a gente vai ter aquela esperança [...] de que o professor vai ser valorizado, mas infelizmente cada dia que passa a gente vê coisas, ouve coisas, né, passa por coisas que vai te desanimando um pouco (Amarilis).

O comentário acima exposto ilustra bem esse misto de sentimentos entre o prazer e o sofrimento no trabalho, em que há uma esperança que serve quase como um conformismo e uma fonte de satisfação para seguir o seu trabalho. É importante que esse sentimento persista, pois são os docentes os formadores de futuros profissionais e, principalmente, de cidadãos, sendo seu papel de educador demasiadamente importante.

A mobilização subjetiva é essencial na busca pela obtenção de prazer ou para a transformação do sofrimento. Propicia o engajamento no trabalho, em que o trabalhador faz uso de sua subjetividade, inteligência prática e do coletivo para tentar transformar as situações adversas do trabalho geradoras de sofrimento (Dejours, 2004b).

Contudo, é preciso lembrar que o sujeito necessita do olhar do outro para (re) significar o seu trabalho, bem como precisa de uma boa organização de trabalho, em que ele consiga dar conta de sua função. Quando tais fatores não se fazem presentes, os docentes acabam por elaborar estratégias como alternativa para preservar sua saúde física/mental e não adoecer.

\section{Estratégias Elaboradas pelos Docentes}

Os docentes buscam estratégias, individuais ou coletivas, para lidar com o sofrimento decorrente das situações adversas do trabalho, na tentativa de evitar o adoecimento e manter o seu equilíbrio psíquico (Dejours, 1992). Isso fica muito bem ilustrado a partir dos comentários verbais dos participantes da pesquisa, em que foi referido que "[...] a grande questão pra ser professor hoje é justamente essa de saber criar mecanismos pra não adoecer".

Nesse sentido, determinadas estratégias podem servir como mantenedoras do emprego, entretanto, sem provocar alguma alteração realmente positiva ao trabalho e/ou ao sujeito (Dejours, 1992), enquanto outras podem ser mais benéficas, propiciando momentos de prazer e espaço para trocas (Perez, 2012). Aquelas são as estratégias defensivas e estas são as estratégias de permanência do sujeito 
no trabalho e as estratégias de mobilização subjetiva e coletiva.

Em relação às primeiras, são destacadas três estratégias enunciadas pelos professores entrevistados, sendo elas: a negação daquilo que gera sofrimento no trabalho; a fuga (ou absenteísmo); e a dissociação afetiva (Mendes, 1995/1996; Perez, 2012). Adota-se a negação como ponto de partida, sendo esta uma estratégia que aparece quando os sujeitos negam aquilo que propicia o sofrimento dentro da organização de trabalho (Perez, 2012). Um dos exemplos evidenciados nas entrevis tas é sobre quando os docentes evitam tratarem algum problema de saúde originado no trabalho, pensando que conseguem lidar sozinhos com o mesmo. Esta acaba sendo uma forma de negar o sofrimento, pois, de certo modo, ignoram o problema de saúde.

Há três anos que eu tinha que tomar medicação, só que eu não aceitei e achei que ia conseguir sem. Só que só foi evoluindo pra pior e chegou num ponto que não deu mais [...] Que nem o médico falou: "é um momento que tu precisa te tratar, te ajudar” [...] Mas eu não pretendo ficar com a medicação. Eu quero conseguir me livrar (Lírio).

Como fica claro, normalmente quando os docentes aceitam a condição de saúde/adoecimento que lhes acomete, muitas vezes o problema de saúde já está agravado, sendo necessário recorrer aos profissionais da saúde e, em elevados casos, o que resta é o afastamento do trabalho, mesmo que por alguns dias. Isso acaba levando à estratégia defensiva de fuga ou absenteísmo, que se refere às faltas ao trabalho, pois por mais que não sejam afastamentos propositais (na maioria das vezes), são momentos em que o sujeito pode aliviar um pouco da sobrecarga e as exigências do trabalho docente.

Portanto, Perez (2012, p. 202) afirma que “[...] o adoecimento é um processo inconsciente à fuga das tensões em torno do trabalho", servindo com um modo de defesa. Mais ainda, é uma forma de o corpo comunicar que se deve diminuir o ritmo de trabalho ou até mesmo parar por um tempo.

\section{[...] eu fiquei internado quase um} mês e depois eu fiz um procedimento cirúrgico [...] aí eu fiquei acho que mais uma ou duas semanas internado com atestado médico (Hibisco).

Tais questões, que acabam remetendo a problemas de saúde, seja por esforços excessivos, seja por falta de reconhecimento nos mais diversos âmbitos, podem fazer prevalecer o desprazer. Ademais, a crescente diminuição dos espaços coletivos e a própria não 
implicação de docentes que já se encontram desanimados, podem levar à dissociação afetiva.

Essa estratégia diz respeito ao enfraquecimento dos vínculos estabelecidos tanto entre professores e alunos, quanto entre os próprios docentes e demais colegas de trabalho, podendo ocasionar em uma individualização ainda maior e falta de cooperação, em que só se faz o estritamente básico das exigências (Santini \& Molina Neto, 2005). Em relação aos colegas de equipe, às vezes aparecem conflitos de ideias, visto que alguns profissiona is demonstram engajamento nas atividades, vontade de lutar por uma educação melhor, enquanto outros já não demonstram muita esperança, gerando contradições no meio escolar. Tulipa evidencia a estratégia de dissociação afetiva, ao relatar certo distanciamento entre ele e alguns colegas, admitindo que prefere que cada um faça o seu trabalho sem muita interação.

Em relação aos colegas eu sinto um pouco de... não desconforto total, mas não é um ambiente que eu possa dizer que pra mim é o melhor de se estar. A minha função é educar alunos. Se o colega gosta de mim ou não, aí fica com os seus problemas, cada um com seus problemas. Não vou atrapalhar na vida deles e ele também não me atrapalham nas minhas aulas $e$ assim a gente continua (Tulipa).

Tais relações estabelecidas no ambiente escolar, em que se tem percebido algumas equipes divididas, demonstram o enfraquecimento dos coletivos e o individualismo se sobressaindo, onde são criadas divergências entre os colegas ao invés de se unirem para fortalecer e melhorar o espaço de trabalho (Bottega, Perez \& Merlo, 2013). Constata-se que muitas das estratégias que têm sido utilizados pelos trabalhadores são bem mais individuais do que coletivas, o que diminui mais ainda as chances de se obter alguma mudança efetiva e torna mais difícil o enfrentamento do sofrimento (Perez, 2012). Contudo, é possível analisar também a existência de estratégias de permanência do sujeito no trabalho (Perez, 2012), que, assim como as defensivas, irão surgir como um modo de lidar com as adversidades do cotidiano do trabalho, com a diferença de que elas são mais positivas ao sujeito. Isso não quer dizer que elas necessariamente irão modificar a organização do trabalho, mas pelo menos propiciarão um ambiente um pouco mais saudável e menos alienante.

Para enfrentar esses conflito s presentes na organização de trabalho, minimizando o sofrimento e evitando $\mathrm{o}$ adoecimento ocorre uma mobilização 
subjetiva dos sujeitos, os quais irão almejar maior engajamento no trabalho e fortalecimento dos vínculos com seus alunos. Deste modo, a partir da pesquisa foi possível constatar algumas estratégias de permanência dos sujeitos no trabalho: bom relacionamento com os alunos; conscientização; e estabelecimento de limites (Perez, 2012).

Nesse tipo de estratégia ocorre o contrário do que vimos nas estratégias defensivas quando nos referimos ao relacionamento com os alunos. Esse foi bastante verbalizado pelos professores, já que eles consideram o vínculo com o aluno muito importante na construção de um ambiente escolar saudável e de aprendizagem, como evidenciado anteriormente. Tendo em vista as adversidades constantes no ensino público, o professor deve ser flexível e, ao mesmo tempo, humano o suficiente para poder acolher os alunos e estabelecer uma boa relação, pautada pelo respeito e compreensão de uns para com os outros (Santini, \& Molina Neto, 2005).

[...] a gente passa no corredor, brinca, fala bobagem e tem grupo no whats. Se eles tiveram vontade de nos colocar no grupo é porque eles nos querem perto. Isso que move, isso não tem o que pague (Gérbera).
É uma questão de: "bem, vamos tentar achar uma maneira, uma nova maneira, uma nova didática, vamos valorizar um pouquinho mais essa gurizada, vamos acreditar nessa gurizada” (Tulipa).

Tendo em vista que os docentes entrevistados enunciaram bastante o fato de prezar por uma boa relação com os alunos e por um ambiente de trabalho que proporcione um convívio saudável com os colegas, constata-se que eles têm dado o seu melhor para que possam se sentir bem com o seu trabalho. Mas é necessário lembrar-se de outros fatores, já abordados, que geram sofrimento e que muitas vezes vão além das possibilidades dos professores, como a falta de reconhecimento e a carga excessiva de trabalho. Assim como alguns tentarão negar tais sintomas, outros poderão dar-se conta do momento pelo qual estão passando, sendo essa estratégia chamada de conscientização (Perez, 2012).

[...] ano passado eu levei um susto... essa crise de ansiedade que me deu, eu fui parar no hospital. Então eu comecei a mudar certas coisas, uma delas a alimentação. Eu não prestava atenção, comia qualquer coisa em qualquer momento, porque é o tempo que tu tem. Só que daí eu comecei a mudar... eu vi que não estava dando certo (Amarilis). 
Às vezes é necessário que o docente apresente algum problema de saúde para refletir sobre fatores que não estão sendo saudáveis em seu trabalho, interferindo em sua vida pessoal e na saúde. Quando essa consciência começa a emergir nos sujeitos, eles são capazes de estabelecer limites em sua rotina de trabalho, na medida do possível, de modo que o trabalho não invada outros espaços de suas vidas, sendo esta outra estratégia de permanência do sujeito (Perez, 2012). Evidenciou-se que alguns dos entrevistados vêm conseguindo encontrar alternativas para manejar o tempo que despendem em função do trabalho.

[...] eu vou pegar trinta minutos do mеи tempo livre que eu estou em casa e vou lá e planejo. Antes eu ocupava muito mais. Dou conta igual com o mesmo tempo que eu determinei, né (Rosa).

[...] eu tento não levar coisas da escola pra casa [...] eu tive que elaborar estratégias pra me organizar melhor [...] porque senão eu vi que eu não ia conseguir (Lírio).

Quando os sujeitos conseguem darse conta do modo como a organização do trabalho influencia em outras esferas de suas vidas e conseguem estabelecer limites (Perez, 2012) para que o seu trabalho não esteja sempre presente na sua vida pessoal, eles conseguem pensar em atividades de lazer, que propiciem bem-estar e qualidade de vida. Esta é uma estratégia acrescentada às demais, pois favorece um espaço de liberação de energias, onde os docentes podem relaxar, cuidar da saúde e se sentirem mais revigorados, trazendo benefícios até mesmo no seu trabalho, já que tais atividades tendem a diminuir as tensões.

Esse ano eu me programei pra caminhar três vezes por semana [...] porque eu preciso cuidar também um pouco de mim, oxigenar o cérebro mesmo, sabe, a gente tem que cuidar da gente (Rosa).

Faço terapia, faço massagem, coisas assim [...] procuro fazer umas meditações, às vezes, pra conseguir carregar esse peso mesmo de todas as dificuldades que são do trabalho, né (Margarida).

[...] ler bons livros, procuro escutar música que eu gosto, passear com a família, fazer exercício (Lírio).

Percebe-se que a atividade física, meditação, psicoterapia e momentos em família são muito importantes para manter o equilibrio psíquico dos docentes, por mais que não tenham a possibilidade de alterar diretamente a organização do trabalho. Talvez não sejam alternativas totalmente desalienantes, mas o fato de os docentes 
conseguirem relaxar pode contribuir para que eles enxerguem o seu trabalho sob outros olhares, não apenas engessados no habitual.

Portanto, nota-se que as estratégias de permanência do sujeito no trabalho demonstram outra maneira de lidar com as adversidades, sendo mais positivas do que as estratégias defensivas. Sendo assim, muitos professores referiram a importância de se ter um lugar para falar sobre as questões da educação e da profissão, em que possam trocar experiências e pensar sobre suas situações em sala de aula. Reconhecem que o espaço de fala é relevante, pois ao "colocar para fora" as palavras, podem perceber determinadas questões.

Nesse sentido, apesar de ficar evidente a necessidade de mais momentos de trocas e organização do tempo para que isso seja viável, é notável o uso de outras estratégias pelos docentes, as quais envolvem um relacionamento positivo entre colegas de trabalho e os espaços alternativos de discussão. Trata-se das estratégias de mobilização subjetiva e coletiva, que se referem ao "modo como os trabalhadores se organizam conjuntamente quando há o objetivo comum de eliminarem o custo negativo que o trabalho lhes impõe" (Anjos, Mendes, Santos, \& Facas, 2011, p. $566)$.

Essas estratégias encontram-se mais próximas da possibilidade de realmente propiciarem mudanças no ambiente de trabalho, já que os docentes buscam maior coesão e integração entre a equipe, em que uns dão suporte aos outros, sendo este um jeito importante de fortalecer os coletivos (Dejours, 1999). Tais estratégias de mobilização subjetiva e coletiva são assim definidas por referirem-se ao investimento pessoal e inteligência prática colocada no trabalho pelo trabalhador, além da cooperação observada no coletivo de trabalho, em que são propiciados espaços de discussão, participação, confiança e consciência de classe (Mendes \& Duarte, 2013; Freitas \& Facas, 2013).

Desse modo, em relação ao relacionamento positivo entre colegas destacam-se as relações positivas que ocorrem entre os docentes, já que a cooperação entre os pares representa um modo eficaz de lidar com as adversidades do trabalho. Assim, os profissionais atuam e pensam como um coletivo, unindo suas forças e propiciando espaços de reflexão.

Ali no currículo a gente sempre conversa, eu tenho uma abertura bem legal com a direção também (Rosa).

Com os colegas o ambiente de trabalho aqui é muito bom. A gente se dá bem, procura se ajudar. Se a gente precisar faltar pra médico a diretora dá um jeitinho (Orquídea). 
Percebe-se que ainda é possível encontrar ambientes de trabalho com respeito e cooperação entre a equipe de trabalho, em que se cria um coleguismo e até mesmo amizades. Os docentes enunciaram a importância de poder contar com os colegas, inclusive quando referem que um ajuda o outro e que há espaço para falar das angústias.

Em consequência dessa relação de equipe, evidencia-se outra estratégia de mobilização subjetiva e coletiva referente aos espaços alternativos de discussão (Perez, 2012). Estes estão relacionados à possibilidade de os docentes se encontrarem fora do espaço de trabalho para terem momentos de lazer, como ir a um bar e falar sobre outros assuntos que não apenas $o$ trabalho. Assim, podem relaxar um pouco e reforçar os laços afetivos com os colegas de trabalho, propiciando resultados positivos à cooperação no cotidiano da escola.

[...] uma pessoa tá com um problema pessoal [...] e as colegas já: "vamos marcar uma coisa pra sair”. Agora tem uma colega que tá meio ruinzinha... sexta-feira elas já marcaram um chopezinho pra de noite, pra levantar a colega (Gérbera).

[...] a gente usa a greve também pra conviver com alguns colegas [...] agora mesmo eu voltei da casa de um desses meus colegas, que a gente tava conversando sobre isso [...] é um modo de tu discutir essas questões e criar esses mecanismos de resistência (Hibisco).

Assim como esses espaços alternativos podem propiciar momentos para falar da vida e não apenas do trabalho, também pode se falar sobre este. Nesse sentido, o espaço de discussão com os colegas serve como uma ferramenta para lidar com as adversidades e até mesmo pode servir como tomada de consciência e busca por mudança (Mendes \& Duarte, 2013).

A partir das estratégias apresentadas é possível perceber que os docentes encontram diferentes modos de lidar com o sofrimento e as adversidades do cotidiano escolar. Algumas apresentam modos mais eficazes de enfrentar a organização do trabalho e preservar a saúde física/mental, principalmente quando há a união do coletivo. Todavia, fica claro que ainda há uma longa caminhada a percorrer, no sentido de buscar maior disponibilidade de espaços para reflexão e suporte entre os profissionais docentes. Só assim eles poderão se fortalecer enquanto categoria e enquanto sujeitos.

\section{Considerações finais}

A pesquisa realizada com os docentes mostrou a centralidade que o trabalho possui na vida dos sujeitos, visto 
que além de eles se sentirem incluídos na sociedade, constituem e transformam a sua subjetividade a partir do trabalho. De mesmo modo, confirma-se na prática o que a teoria já revela sobre a dinâmica de prazer e sofrimento presente nas organizações do trabalho.

Além disso, notou-se que mesmo com as transformações no mundo do trabalho e com a criação de diretrizes cujo objetivo é garantir melhores condições de trabalho, os docentes ainda sentem-se desamparados em muitas situações, principalmente no que diz respeito à sua autonomia e ao reconhecimento da categoria. Inclusive, é possível perceber que muitos desses profissionais têm a percepção de que antigamente os professores eram mais valorizados e respeitados pela sociedade, sendo vistos como autoridades.

Contudo, ficou evidente o quanto os alunos motivam os docentes a continuarem trabalhando, já que se sentem reconhecidos ao receberem elogios, abraços e demais demonstrações de afeto, enunciando a importância do vínculo com os alunos no ambiente de trabalho. Portanto, constata-se que o reconhecimento pelo outro, no trabalho, constitui um fator importante para que se exerça a profissão, fazendo com que o sujeito (re) signifique a sua experiência, conseguindo transformar o sofrimento em prazer.
Nesse sentido, é exaltada a importância de voltarmos a nossa atenção para a categoria docente, a fim de valorizála e reconhecê-la da maneira como merece, fazendo parte de suas lutas, já que se trata também de uma luta pela educação. É importante, ainda, que os docentes possam criar espaços alternativos de discussão para refletir sobre o trabalho e sobre sua subjetividade, fortalecendo sua categoria, repensando e (re) significando o seu trabalho. Assim, estarão mais conscientes e poderão dar-se conta de algumas estratégias (sejam defensivas, de permanência do sujeito no trabalho ou de mobilização subjetiva e coletiva) que utilizam para evitar o sofrimento e não adoecer, sendo possível, juntos, criarem novas possibilidades.

O prazer em ver o desenvolvime nto e crescimento dos alunos foi um comentário que se destacou durante as entrevistas, demonstrando o quanto isso gera satisfação aos professores e os motiva a seguir em frente, com a esperança de que a educação ainda receba seu devido reconhecimento. Como escreveram Codo e VasquesMenezes (2002, p. 41), “qualquer ser humano sonha, pelo menos por um momento, em escrever seu nome na história, em última instância, em não morrer, em ser lembrado depois que passou. O professor, o educador, tem essa chance". Esta citação define muito do sentimento apresentado pelos docentes, em que 
percebem que seu trabalho tem um sentido e de que serão importantes na vida de muitas pessoas.

\section{Referências}

Anjos, F. B. (2013). Organização do Trabalho. In: Vieira, F. O., Mendes, A. M., \& Merlo, A. R. C. Dicionário crítico de gestão e psicodinâmica do trabalho. Curitiba: Juruá.

Anjos, F. B., Mendes, A. M., Santos, A. V., \& Facas, E. P. (2011). Trabalho prescrito, real e estratégias de mediação do sofrimento de jornalistas de um órgão público. Revista Eletrônica Sistemas \& Gestão, 6, 562-582. Recuperado de http://lpct.com.br/wpcontent/up loads/2012/11/2-Santosjunior_trabalho-prescrito.pdf

Baldin, N., \& Munhoz, E. M. B. (2011, novembro).Snowball (bola de neve): uma técnica metodológica para pesquisa em educação ambiental comunitária. Anais do X Congresso Nacional de Educação; I Seminário Internacional de Representações Sociais, Subjetividade e Educação, Curitiba, PR, Brasil, 329-341. Recuperado de http://www.educere.bruc.com.br/CD2 011/pdf/4398_2342.pdf

Bottega, C. G. (2015). Clínica do trabalho no sistema único de saúde: linha de cuidado em saúde mental do trabalhador e da trabalhadora (Tese de doutorado). Programa de PósGraduação em Psicologia Social e Institucional da Universidade Federal do Rio Grande do Sul, Porto Alegre, RS, Brasil. Recuperado de https:/lume.ufrgs.br/handle/10183/14 $\underline{1121}$

Bottega, C. G., Perez, K. V., \& Merlo, A. R. C. (2013). Saúde Mental e trabalho: uma construção histórica. Revista AMAzônica,
Amazonas, 11(2), 261-281. Recuperado de https $/ /$ dialnet.unirioja.es/servlet/articulo?c $\underline{\text { odigo }=4710243}$

Codo, W., \& Vasques-Menezes, I. (2002). Educar, educador. In W. Codo. (Org.). Educação:carinho e trabalho. Petrópolis, RJ: Vozes.

Dejours, C. (1992). A loucura do trabalho:estudo de psicopatologia do trabalho (5a ed.) São Paulo: Cortez.

Dejours, C. (1999). A Banalização da Injustiça Social. Rio de Janeiro: Fundação Getúlio Vargas.

Dejours, C. (2004a). A metodologia em psicopatologia do trabalho. In $\mathrm{S}$. Lancman, \& L. Sznelwar. (Orgs.). Christophe Dejours: $d a$ Psicopatologia à Psicodinâmica do Trabalho.Rio de Janeiro: Fiocruz.

Dejours, C. (2004b). Subjetividade, trabalho e ação. Revista Produção, 14(3), 27-34. Recuperado de http://www.scielo.br/pdf/prod/v14n3/v 14n3a03.pdf. doi:10.1590/S01036513200400030000 $\underline{4 .}$

Dejours, C., Abdoucheli, E., \& Jayet, C. (1994). Psicodinâmica do Trabalho: contribuições da escola dejouriana à análise da relação prazer, sofrimento e trabalho. São Paulo, SP: Atlas.

Duarte, F. S., \& Mendes, A. M. B. (2015). Psicodinâmica do Trabalho do coletivo de profissionais de educação de escola pública. Psico-USF, Bragança Paulista, São Paulo, 20(2), 323-332. Recuperado de

http://www.scielo.br/pdf/pusf/v20n2/1 413-8271-pusf-20-02-00323.pdf

Freitas, L. G., \& Facas, E. P. (2013). Vivências de prazer-sofrimento no contexto de trabalho dos professores. Estudos e pesquisas em psicologia, Rio 
de Janeiro, 13(1), 7-26. Recuperado de http://www.scielo.br/scielo.php?script $=$ sci $\operatorname{arttext} \& p i d=S 141323112013000$ 200010

Guzzo, R. S. L., Mezzalira, A. S. C., \& Moreira, A. P. G. (2014). Desafios, ameaças e compromissos para os psicólogos: as políticas públicas no campo educativo. In I. F. Oliveira, \& O. H. Yamamoto. (Orgs.). Psicologia e politicas sociais:temas em debate. Belém: UFPA, 215-232.

Heloani, R., \& Lancman, S. (2004). Psicodinâmica do Trabalho: o método clínico de intervenção e investigação. Revista Produção, São Paulo, 14(3), 77-86. Recuperado de http://www.scielo.br/pdf/prod/v14n3/v 14n3a08.pdf. doi:10.1590/S01036513200400030000 $\underline{9}$

Mattos, E. C. (2016). Prazer e sofrimento no trabalho bancário: um olhar sobre o gestor intermediário (Dissertação de mestrado). Programa de PósGraduação em Psicologia Social e Institucional da Universidade Federal do Rio Grande do Sul, Porto Alegre, RS, Brasil. Recuperado de https://ume.ufrgs.br/handle/10183/14 $\underline{1491}$

Mendes, A. M. B. (1995-6). Comportamento defensivo: uma estratégia para suportar o sofrimento no trabalho. Revista de Psicologia, Fortaleza, 13/14(1/2), 27-32. Recuperado de http://www.repositorio.ufc.br/handle/riufc/ $\underline{11111}$

Mendes, A. M. B. (2007). Psicodinâmica do Trabalho:teoria, métodos e pesquisas. São Paulo: Casa do Psicólogo.

Mendes, A. M. B., \& Duarte, F. S. (2013). Mobilização subjetiva. In: Vieira, F. O., Mendes, A. M., \& Merlo, A. R. C.
Dicionário crítico de gestão $e$ psicodinâmica do trabalho. Curitiba: Juruá.

Neves, M. Y. R., Seligmann-Silva, E. (2006). A dor e a delícia de ser (estar) professora: trabalho docente e saúde mental. Estudos e pesquisas em psicologia, Rio de Janeiro, 6(1), 63-75. Recuperado de http://www.epublicacoes. uerj.br/index. php/revispsi/article/view/11082/8759

Oliveira, L. J., \& Pires, A. P. V. (2014). Da precarização do trabalho docente no Brasil e o processo de reestruturação produtiva. Revista do Direito Público, Londrina, 9(1), 73-100. Recuperado de http:/www.uel.br/revistas/uel/index.p $\mathrm{hp} /$ direitopub/article/view/17128. doi:10.5433/1980-511X.2014v9n1p73

Perez, K. V. (2012). "Se eu tirar o trabalho, sobra um cantinho que a gente foi deixando ali": Clínica da Psicodinâmica do Trabalho na atividade de docentes no ensino superior privado(Dissertação de mestrado). Programa de PósGraduação em Psicologia Social e Institucional da Universidade Federal do Rio Grande do Sul, Porto Alegre, RS, Brasil. Recuperado de http://www.lume.ufrgs.br/handle/1018 $\underline{3 / 70043}$

Perez, K. V. (2017). "Entre o real e o ideal, existe o possivel": a proposta da clínic a do trabalho institucional como dispositivo de atenção à saúde mental dos profissionais e usuários do sistema único de saúde (SUS). (Tese de doutorado). Programa de PósGraduação em Psicologia Social e Institucional da Universidade Federal do Rio Grande do Sul, Porto Alegre, RS, Brasil. Recuperado de https://lume.ufrgs.br/handle/10183/18 $\underline{0998}$ 
Santini, J., \& Molina Neto, V. (2005). A síndrome do esgotamento profissional em professores de educação física: um estudo na rede municipal de ensino de Porto Alegre. Revista Brasileira de Educação Física e Esporte, São Paulo, 19(3), 209-222. Recuperado de http://www.revistas. usp.br/rbefe/articl e/view/16596. doi:10.1590/S18075509200500030000 $\underline{4}$

Silveira, D. T., \& Córdova, F. P. (2009). A pesquisa científica. In T. E. Gerhardt, \& D. T. Silveira. (Orgs.). Métodos de Pesquisa. Porto Alegre: UFRGS, 3142. Recuperado de http://www.ufrgs.br/cursopgdr/downlo adsSerie/derad005.pdf

Tumolo, P. S., \& Fontana, K. B. (2008). Trabalho docente e capitalismo: um estudo crítico da produção acadêmica da década de 1990. Educação \& Sociedade, Campinas, 29(102), 159180. Recuperado de http://www.scielo.br/pdf/es/v29n102/a 0929102.pdf. doi:10.1590/S010173302008000100009

Data de Submissão: 06/06/2018

Data de Aceite: 21/09/2018 